D1.2:ES 8/944-78

\title{
THE DEPARTMENT OF DEFENSE
}

\author{
Documents on \\ Establishment and Organization \\ 1944-1978
}

Edited by

Alice G. Cole

Alfred Goldberg

Samuel A. Tucker

Rudolph A. Winnacker

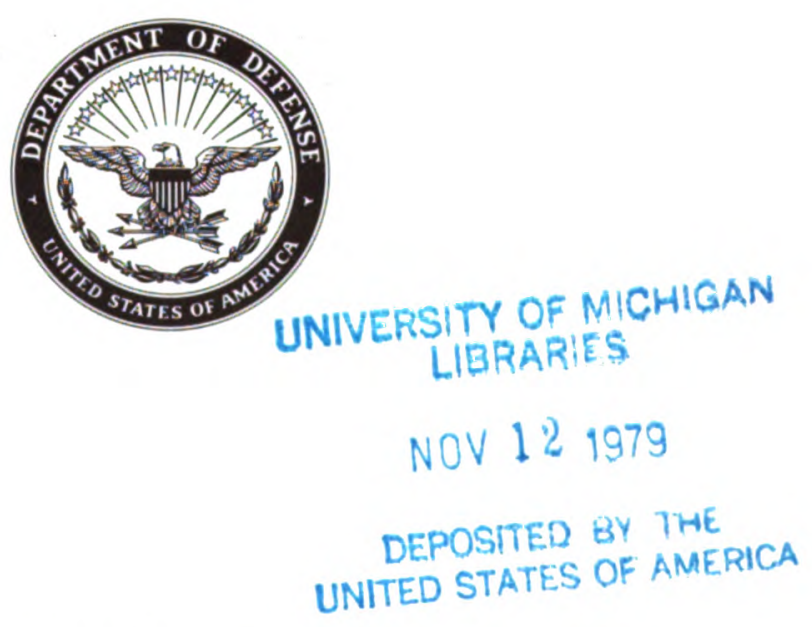

OFFICE OF THE SECRETARY OF DEFENSE

HISTORICAL OFFICE

Washington, D.C. • 1978 